\section{SCA mit neuem Geschäftsbereichsleiter}

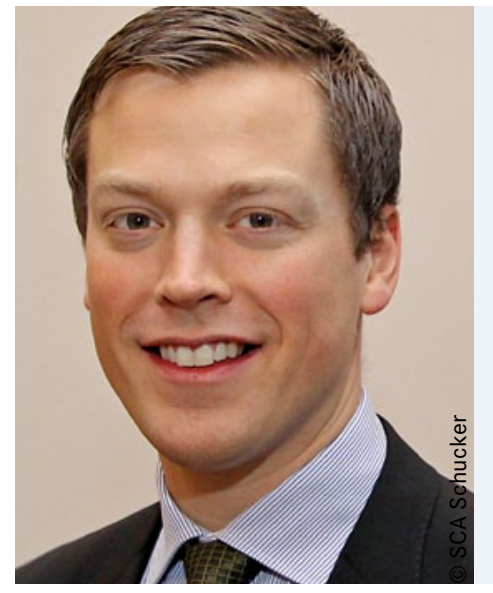

Oskar

Sörensso, neuer

Geschäftsbereichs-

leiter Allgemeine

Industrie bei SCA in

Bretten

O

skar Sörensson hat am 1. März bei der SCA Schucker GmbH \& Co. KG in Bretten die Leitung des Geschäftsbereichs Allgemeine Industrie übernommen. SCA ist mit seinen Klebtechnik-Systemen bislang vor allem in der $\mathrm{Au}-$ tomobilindustrie vertreten. Sörensson soll den noch jungen Geschäftsbereich Allgemeine Industrie ausbauen und die Expansion in Branchen unterstützen, die durch den Einsatz von Leichtbaumaterialien ebenfalls einen hohen Bedarf an Kleb-, Dichtungs- und Dämmtechnologie haben.

Der 33-Jährige studierte Wirtschaftsingenieurwesen im schwedischen Linköping und an der Technischen Universität Darmstadt. Sörensson war zuvor bei Atlas Copco Tools \& Assembly Systems in Stockholm als Produktmanager mit globaler Verantwortung und zuletzt als Marketingleiter Fahrzeugindustrie bei Atlas Copco Tools in Essen tätig.

SCA gehört seit August 2011 zum schwedischen Industriekonzern Atlas Copco und hat weltweit mehr als 400 Mitarbeiter. Atlas Copco ist als Gesamtkonzern mit etwa 40000 Mitarbeitern in rund 180 Ländern vertreten.

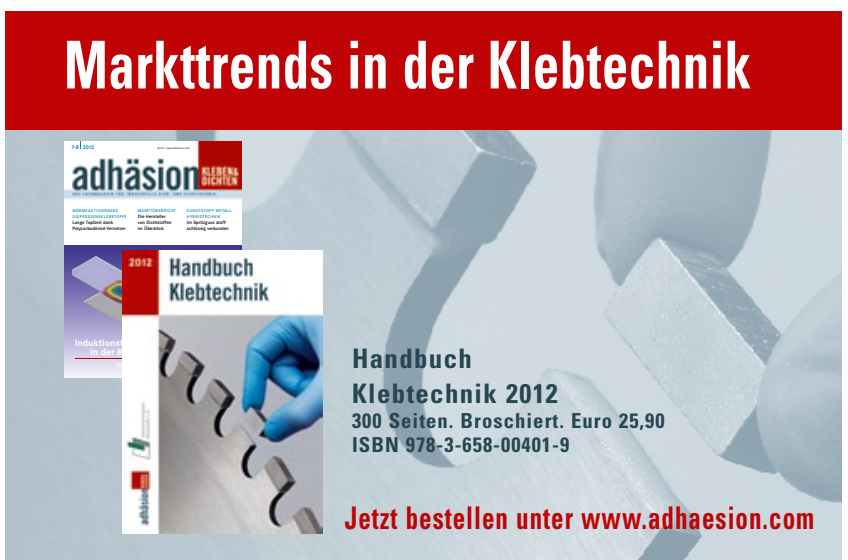

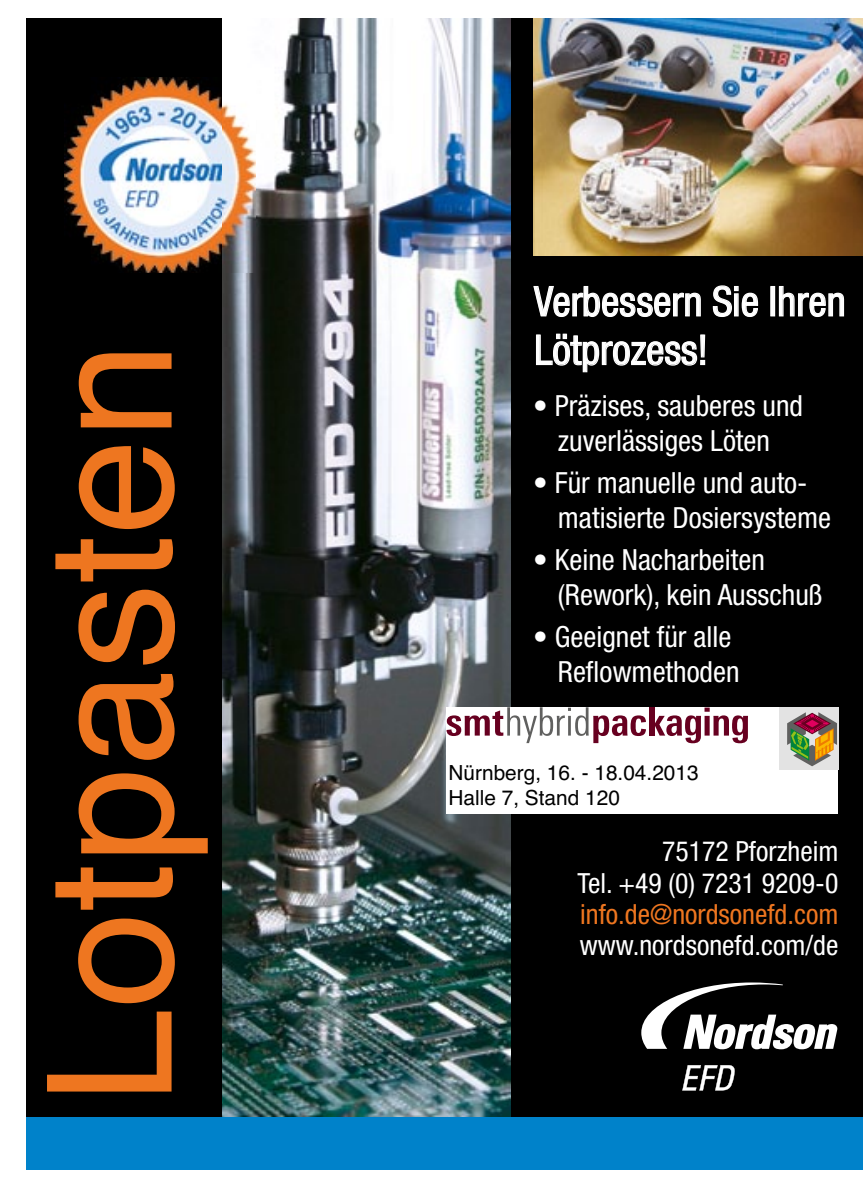

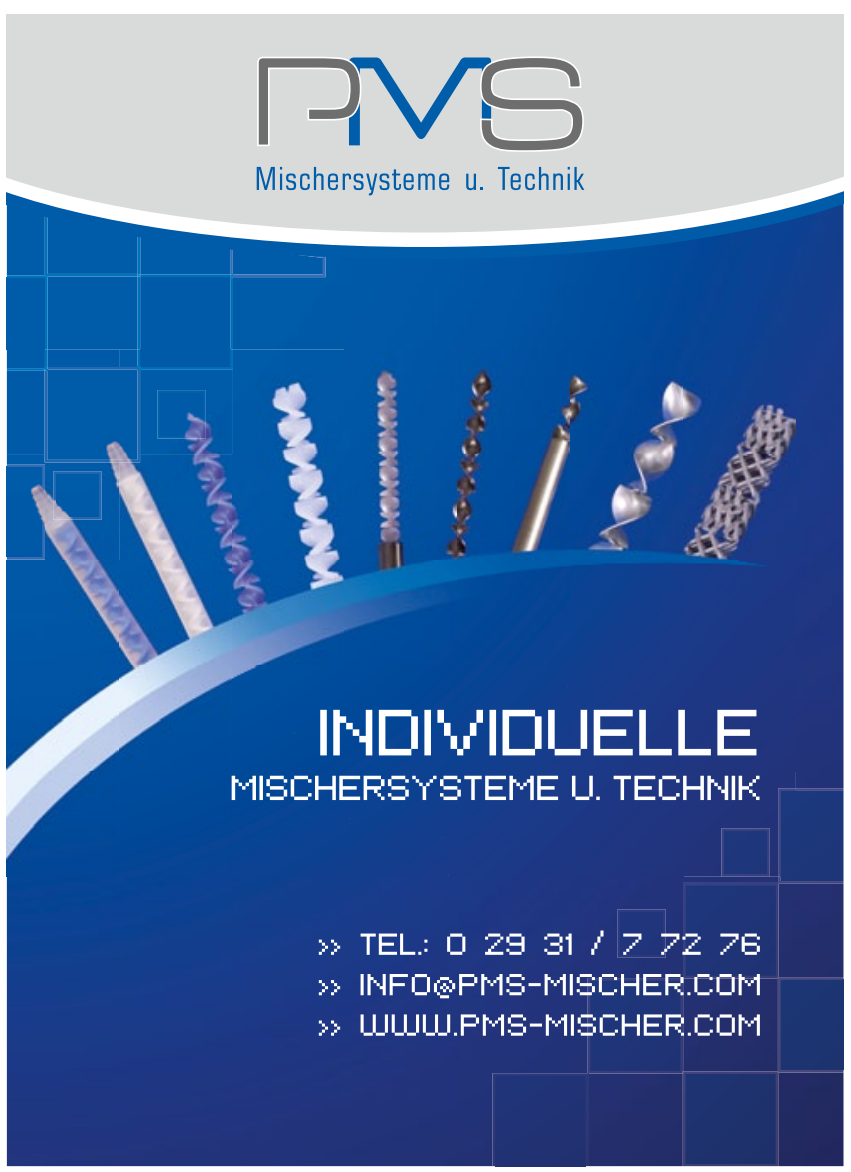

